


\title{
JOYCE, EL ARTISTA MIRADO POR LAS PALABRAS
}

\author{
JOYCE, THE ARTIST LOOKED BY THE WORDS
}

María Cecilia Salas Guerra

\begin{abstract}
RESUMEN
En el Retrato del artista adolescente, Joyce asume la tarea de hacerse un nombre, al tiempo que confiesa la ajenidad frente al cuerpo y muestra la temprana conciencia del lenguaje. Interesa mostrar cómo, frente a esta novela, Umberto Eco insiste en el ropaje escolástico, o la mentalidad medieval transversal en la obra de Joyce, concluyendo que el irónico "retrato del tomista adolescente" no coincide tanto con el Joyce de Ulysses, sino que es el retrato de una "situación cultural" reconocida por el escritor irlandés y dotada de objetividad (Eco, 2000, p. 58). Por su parte, Jacques Lacan (2013) privilegia en esta novela, hecha con recuerdos infantiles, la función que cumplen allí la letra y el cuerpo. El artista adolescente deja caer el cuerpo, al tiempo que se desliza en una cascada de letras y palabras que parecen mirarle de frente. Es así como surge el joven artista de la caída y de la letra, con nombre de mártir-inventor, cristiano-pagano, saint homme-sinthome, augur y hacedor de laberintos: Stephen Dedalus.

Palabras clave: escritura; cuerpo; letra; Joyce; Retrato del artista adolescente.
\end{abstract}

\begin{abstract}
In A portrait of the Artist as a Young Man, Joyce assumes the task of making a name, while confesses the strangeness in front of the body and shows the early awareness of the language. It is interesting to show how, in the face of this novel, Umberto Eco insists on the scholastic dress, or the transverse medieval mentality in Joyce's work, concluding that the ironic "portrait of the adolescent tomist", does not coincide with Joyce's Ulysses, but that it is the portrait of a "cultural situation" recognized by the Irish writer and endowed with objectivity (Eco, 2000, p. 58). On the other hand, Jacques Lacan (2013) privileges in this novel, made with children's memories, the function that the letter and the body fulfill there. The adolescent artist drops the body, while slips in a cascade of letters and words that seem to look you in the face. This is how the young artist of the fall and the letter emerges, with the name of martyr-inventor, Christian-pagan, saint homme-sinthome, augur and labyrinth maker: Stephen Dedalus.
\end{abstract}

Keywords: writing; body; letter; Joyce; A portrait of the Artist as a Young Man.

Dra. María Cecilia Salas Guerra. Profesora y coordinadora de la Maestría y el Doctorado en Estética. Departamento de Estudios Filosóficos y Culturales. Universidad Nacional de Colombia, sede Medellín. Colombia.

Correo electrónico: mcsalasg@unal.edu.co

Recepción: 29- 05- 19

Aceptación: 02- 09- 19 
Aquellas letras grabadas en la manchada madera del pupitre le estaban contemplando fijamente, como si hicieran befa de su flaqueza corporal y de sus fútiles entusiasmos, le provocaran a la repugnancia de su propia locura y de las asquerosas orgías de su mente. Joyce (2012, pp. 122-123).

¿Que Joyce sea por excelencia el escritor del enigma no sería la consecuencia del ensamblaje tan mal hecho de este ego, de función enigmática, de función reparadora?

Lacan (2013, p. 151)

\section{Introducción 1}

James Joyce es un maestro del equívoco, de la ocurrencia y la agudeza; se abisma, y con él sus lectores, no solo en indescifrables calambures sino en su prodigioso laberinto construido palabra por palabra, letra por letra. Desde sus ensayos juveniles, hasta Finnegans Wake, el autor lleva al límite el arte de destrozar y descomponer las palabras, de pulverizarlas y tomarlas con virulencia - pulverulencia, dirá Colette Soler (2003)-. Tal como él mismo advierte, su obra "no cesará de dar trabajo a los universitarios", y lo hará por lo menos durante "trescientos años" (Joyce, citado por Lacan, 2013, p. 161), y es así como no dejó de cautivar a grandes autores como Samuel Beckett, T. S. Eliot, Italo Svevo, Frank McCourt, Henri Miller, Jorge Luis Borges, Philip K. Dick, entre otros. Y, al mismo tiempo, no deja de proliferar en torno suyo la incansable labor de la crítica especializada en procura de descifrar, hallar sentido, establecer referencias para cada asunto, cada personaje y cada juego de palabras.

A Umberto Eco, en Las poéticas de Joyce (2000), le interesa mostrar la influencia de Santo Tomás de Aquino, Ibsen y los simbolistas en la actitud y en la obra de Joyce, desde su temprano ensayo "El estudio de las lenguas". Eco distingue tres etapas en lo que denomina el proyecto de Joyce: la escritura juvenil marcada por la teoría de la impersonalidad poética; la escritura de Ulysses, en la cual la técnica, la forma y el contenido poético son indiscernibles; y la poética de Finnegans Wake, donde la historia de las palabras es la historia de los hombres.

Sobre la obra del irlandés, Jacques Lacan dirá que "Nunca se había hecho literatura así [...] Letter, litter, la letra es el basurero"; más aún, después "la literatura ya no puede ser lo que había sido" (2013, pp. 163 y 165). En el Seminario 23: El Sinthome (2013[1975-6]), Lacan introduce nuevos énfasis en la lectura de Joyce, con lo cual no solo se amplía la comprensión de esta obra, sino que, sobre todo, se potencia la teoría psicoanalítica, pues la lectura de Joyce es crucial para la compleja elaboración lacaniana del sinthome y del nudo borromeo.

Este texto se ocupa del lugar del cuerpo y de la letra en Retrato del artista adolescente, es decir, de la peculiar desestimación del cuerpo en contraste con el estatuto privilegiado que tiene la letra para Joyce. Asunto más o menos soslayado por la crítica, incluida la de Eco, pero destacado por Lacan como clave de lectura de Joyce. La primera tentativa de escribir "Retrato del artista" -título sugerido por su hermano Stanislaus- la lleva acabo el 7 de enero de 1904, con escasos veintidós años, pero el ensayo fue rechazado para su publicación. Sin embargo, la idea escribir una autobiografía exhaustiva se arraiga aún más en el joven Joyce y enseguida emprende aquella gran confesión personal que será Stephen el héroe, en la cual trabajará hasta 1907,

$1 \quad$ El presente texto es un producto del proyecto de investigación colectiva: Transversalidades estéticas en la esfera semiótica. Elementos para un análisis semio-estético de las artes. Universidad Nacional de Colombia, sede Medellín, código HERMES 34682. 
simultáneamente con la serie de relatos que conformarán luego Dublineses -algunos de ellos publicados en el semanario Irish Homestead, pero en su conjunto solo se publicarán en 1914-, proyecto anunciado por Joyce como una Epicleti, deformación de Epiclesis o invocación ortodoxa del Espíritu Santo para que transforme la hostia en el cuerpo y la sangre de Cristo. En estos relatos consagra las revelaciones súbitas que le llegan a través de insustanciales acontecimientos cotidianos de la decadente ciudad de Dublín, la cual es reflejada como centro de la parálisis y la hemiplejia de Irlanda. Stephen el héroe, en cambio, solo se publicará póstumamente. Hacia 1907, instalados en Zurich desde 1905, su esposa Nora Bernacle se haya embarazada de su segundo hijo, y entre tanto Joyce decide re-escribir Stephen el héroe en cinco capítulos, pero lo quiere hacer bajo el nuevo título de Retrato del artista adolescente. Este recomienzo de la labor de gestación del espíritu del artista avanza hasta 1908, cuando se verá estancado en tres capítulos. Para continuar y llegar hasta los cinco capítulos previstos será necesario, en primer lugar, el encuentro con Italo Svevo (Ettore Schmitz). Retirado de la literatura y dedicado a los negocios, Svevo estudia inglés en Berlitz School, donde será alumno de Joyce. Después de leer Senilidad y Una vida, Joyce le dice a Svevo: "es usted un autor subvalorado, hay pasajes en Senilidad que ni Anatole France los hubiera escrito mejor" (cita en Ellmann, 2002, p. 302). Estas palabras reconectan a Svevo con la literatura, mientras que la elogiosa lectura que Svevo hace de los tres capítulos del Retrato será un gran impulso para el irlandés. Svevo se fascina con la narración de los sermones que develan cómo fue la educación de Joyce y cómo este transita por la religión antes y después del pecado. El autor de Senilidad también escribe un entrañable ejercicio de composición en inglés acerca de cómo ve a su joven maestro, que, por encima de todo, disfruta de caminar entregado al ocio.

Nadie lo espera y él no quiere llegar a una meta ni encontrarse con nadie. ¡No! Camina para que lo dejen solo.
Tampoco camina porque sea saludable. Camina porque nada lo detiene. Me imagino que si encontrara el paso
cerrado por una pared alta y gruesa ni se inmutaría. [...] Usa gafas sin interrupción... Quizá vea menos que lo que
puede suponerse por su aspecto, pero parece como si fuese un ser que se mueve para ver. Ciertamente es capaz de
combatir y no quiere hacerlo. Atraviesa la vida con la esperanza de no encontrarse con hombres malos. Yo le deseo
de todo corazón que no se los encuentre (Svevo, 1990, pp. 40-1).

Y, en segundo lugar, será necesario también el viaje que hará a Dublín en el verano de 1909, acompañado por su pequeño Giorgio, y de donde regresa con gran cantidad de materia prima -personajes, traiciones, rencillas e intrigas- para el Retrato y para Ulysses. De este viaje, no solo se lleva a Irlanda consigo hacia el propio exilio, sino también el mundo de su infancia, en el cual predominan y resuenan vivos los dichos y los dislates del padre, y la piedad mariana y sacrificial de la madre.

Joyce publicará su novela por entregas en 1914-5 en la revista The egoist, y como libro aparecerá en 1916. Con un estilo y una tonalidad marcada por la tensión entre el abatimiento y la lucidez extática, Joyce decanta y reelabora acontecimientos de su familia, de su infancia y su adolescencia, vivida entre un gran número de hermanos, con un padre fracasado: desordenado con el dinero, alcohólico, inconstante, sin oficio ni profesión definida, y una madre ultracatólica y enfermiza. Al mismo tiempo, se encuentran las peripecias de su formación con los jesuitas y los hermanos cristianos, marcada en alguna medida por al franco declive económico de la familia, pero también expuesta al ruido que supone la politización de la vida cotidiana, sobre todo cuando se produce una mezcla perniciosa de política y religión bajo la forma de nacionalismo a ultranza. Quizá por ello, su hermano Stanislaus, el benevolente agnóstico, en su libro Mi hermano Joyce - My brother's keepers, se refiere a Dante para 
recordar que la naturaleza no procede a saltos y que "crear la pequeña flor del genio es labor de siglos. Esa pequeña flor, con alarmante frecuencia, crece en medio de la decadencia, y el vigoroso vástago de un tronco seco" (Joyce, 2000, p. 43). Además de brotar al término de una época decadente y de inmortalizar la vida cotidiana, simple e intrascendente de una ciudad como Dublín, es preciso decir que la obra de Joyce también lleva el germen de los dichos y los sinos que atraviesan "el tronco que dio esa curiosa y robusta flor" (Joyce, 2000, p. 43).

\section{Drama y epifanía} Trataba de captar en sus poesías el más elusivo de sus estados de ánimo y organizaba cada verso no
palabra por palabra sino letra por letra [...] incluso permutaba y combinaba las cinco vocales para
construir los gritos de las emociones primitivas.
Joyce (1978, p. 25).

Por su escritura impecable, a los doce años James Joyce gana el primer premio, luego vendrán otros más, los mismos que van a parar a ese barril sin fondo que son las finanzas de la familia; los premios que recibe siempre son A mojorem Dei gloriam y al final L.D.S: Laus Deus Semper. Será su profesor de inglés G. Dempsey -Mr. Tate en el Retrato- quien lo recomienda con el director de estudios como un joven en extremo imaginativo, que seguro será escritor.

Así se va gestando la peculiar escritura de Joyce, en medio de múltiples precariedades y vicisitudes domésticas, que no se ocultan ni por la mayor gloria de Dios. Su espíritu se fue labrando entre la fascinación y el amor incondicional por el insubsistente padre -que delega su función en la formación del hijo en los jesuitas, Caballeros de la Educación-, y la pasión temprana y desmedida por Ibsen, en directa proporción a la fuerte aversión hacia toda visión romántica de la vida y del mundo.

En el Belvedere, Joyce llega a ser el mejor estudiante del curso superior, convirtiéndose en una ciudadela o castillo inexpugnable, que podía prescindir de la educación religiosa y de la disciplina jesuita, de donde, no obstante, había extraído el conocimiento de varias lenguas. Ahora, lo suyo es la vida y el arte, que a la postre asume como una misma cosa, aunque con ello esté garantizado el caos y el sufrimiento. "Vivir, errar, triunfar, crear vida de la vida" (Joyce, 2012, p. 235), dirá en el Retrato.

En 1898 ingresa en el University College, y allí puede respirar un jesuitismo laxo, que le permite avivar su pasión por los grandes italianos: Dante, D’Annuncio, Cavalcanti, y Giordano Bruno, del cual, en el Retrato, hará una defensa cuando Ghezzi le recuerda que era un "terrible hereje", "sí, y terriblemente quemado" (Joyce, 2012, p. 345), contestará Stephen Dedalus. El maestro Carlo Ghezzi -jesuita italiano que había vivido en la India- reconoce rápidamente el interés del joven por la estética y lo anima a escribir un ensayo sobre la materia. Acorde con Santo Tomás de Aquino, el joven Joyce asume que la belleza reside en el placer al contemplar las cosas. Pero intenta separar esta idea de la otra que también defiende Aquino sobre las causas finales, para utilizarla como argumento a la hora de excluir la instrucción como una de las finalidades del arte. De modo que acepta lo verdadero y lo bello, pero deja lo bueno en vilo, no porque predique la inmoralidad del arte sino porque rechaza la estrechez del didactismo. En su propósito de escribir un ensayo sobre estética, Joyce toma notas durante mucho tiempo, incluso en la Biblioteca de París en su primera estancia, en 1903, pero finalmente desiste de ello y, 
mucho después, en el Retrato, pondrá en boca Stephen Dedalus una larga consideración sobre la materia, sobre lo cual su amigo Cranly ${ }^{2}$ será el paciente escucha.

La distancia creciente de Joyce frente a la familia, la política y la religión -distancia que en Stephen el héroe se defiende como el principio de la economía artística- está exenta de rabia, pues el irlandés nunca estuvo realmente atado a estas tres instituciones como para resultar luego enfurecido o decepcionado de ellas. Evasivo y ambiguo ante la iglesia, ¿la abandona, la niega, la trasmuta? Cuando en el Retrato Stephen es interpelado en este sentido, sus respuestas son equívocas. A diferencia de su hermano Stan, que combate a la Iglesia abiertamente como un cruzado, Jim prefiere despreciar que combatir. "Ya no era cristiano, pero acomodó el templo para nuevos usos en lugar de tratar de derrumbarlo, considerándolo como una forma superior de la locura humana que, al ser interpretada por un artista laico, contenía oscuros fragmentos de verdad" (Ellmann, 2002, p. 84). Como Ibsen, detesta igualmente el nacionalismo en todas sus expresiones, y en cambio prefiere el arte sobre todo tipo de actividad humana. En esta "iglesia sin credo" que está fundando será "inflexible y arrojado" (Ellmann, 2002, p. 84).

En 1900, con 18 años, Joyce se rehúsa estudiar una profesión rentable, vagabundea, pierde sus becas y no hace nada, como tampoco lo hace su padre, para remediar en algo la precariedad económica de la familia. Pero lo importante es que escribe "Drama y vida", siguiendo en alguna medida las ideas tomistas sobre lo bello, sin que la ética y lo bueno tengan cabida allí. Defiende el drama por encima de las demás formas literarias. El drama es juego de pasiones, contienda, movimiento; existe antes que la forma, es un espíritu, un demonio, "surge de la vida, es coetáneo de ella", es instinto aplicado a la mente, por eso no tiene como finalidad instruir, edificar, o divertir, tampoco es la belleza su propósito, esta es, a veces, "anémica espiritualidad, otras veces simple animalidad". Sería arriesgado afirmar que el drama deba subordinarse a la belleza, pues este es la "swerga de los estetas", es decir, el cielo de los dioses, según la literatura hindú (Joyce, 1971, p. 61). Si el drama es coetáneo de la vida, y esta se presenta "triste y aburrida en nuestros días" (Joyce, 1971, p. 63), entonces se impone ser consecuente en el drama:

[...] creo que de la terrible monotonía de la vida se puede extraer un poco de esencia dramática. Incluso la gente más vulgar, los más muertos entre los vivientes, puede tener su papel en un gran drama. Es una pecaminosa insensatez suspirar por los buenos tiempos pasados, saciar nuestra hambre con las frías piedras que nos ofrecen. Debemos aceptar la vida tal como se presenta a nuestros ojos, y a los hombres y mujeres tal como los encontramos en el mundo real, y no tal como lo intuimos en un mundo fantasioso. La gran comedia humana en la que todos y cada uno participamos, ofrece terreno sin límites al artista verdadero hoy al igual que ayer [...] las inmortales pasiones, las humanas verdades que hallaron expresión otrora, son realmente inmortales, inmortales en el ciclo heroico o en la edad de las ciencias (Joyce, 1971, pp. 63-64).

Jonh Francis Byrne -Cranly en el Retrato- es el gran amigo del joven Joyce. Bello, inteligente, ajedrecista, de ideas "atrevidamente comunes", indiferente a la afectación que reina en el Belvedere. Tenía el valor de ser sencillo, de ir por el mundo como quien conoce todos sus secretos, "pero declina ejercer el poder que posee" (Ellmann, 2002, p. 82). No aventura comentarios, y cuando Joyce manifestaba sus opiniones acerca de la religión, la filosofía y los amigos, sus comentarios "se estrellaban como las olas contra la críptica taciturnidad de Byrne. Escuchaba la charla y las confidencias de Joyce sin ofrecer ninguna propia, y, como Joyce comentó alguna vez, sin ofrecer la absolución" (Ellmann, 2002, p. 82). Este temprano amigo que supo reenviar a Joyce a sus asuntos, y que no en vano tiene reservadas muchas páginas en el Retrato, escribió luego el libro que Ellmann juzga como el mejor entre los que han escrito los amigos de Joyce: Silent years (1953). 
Se trata para el artista, de comprender la propia situación, emprender el propio camino y, con ayuda del arte, es decir, del drama, construir "nuestros lugares de descanso, con más clara visión interior y mayor previsión", con piedras sólidas y "ventanas amplias y limpias" (Joyce, 1971, p. 4).

También en 1900, Joyce escribe "El nuevo drama de Ibsen", comentando la obra Cuando despertemos de entre los muertos. Resonancias de este ensayo las tendremos en "Los muertos" y en el capítulo cuarto del Retrato. Aunque aquí defiende el drama por encima de la literatura, en el Retrato dirá que "la literatura es el más elevado y espiritual arte". Ibsen, con su gran conocimiento de la mujer, representa el drama en su desnudez, solo se ocupa de las vidas corrientes, mira todo con sobriedad, comprensión y simpatía: “con visión perfecta y angélico desapasionamiento, con la visión de quien es capaz de mirar el sol con los ojos abiertos de par en par" (Joyce, 1971, p. 91). En el Retrato, la personalidad del artista es grito, humorada, canción, narración fluida, hasta llegar a "evaporarse por fuera de la existencia, a impersonalizarse [...] el artista, como el Dios de la creación permanece dentro, o detrás o más allá, o por encima de su obra, transfundido, evaporado de la existencia... indiferente... entretenido en arreglarse las uñas" (Joyce, 2012, p. 296).

Por "El nuevo drama de Ibsen", Joyce recibe del escritor noruego una carta de reconocimiento, tan significativa para él que sentirá que deja de ser irlandés para ser europeo. Ahora, su amigo Oliver Gogarty le llama el Dante ${ }^{3}$ de Dublín. Se entrega entonces con ahínco a la escritura, aprende danés por Ibsen y alemán por Hauptmann. Busca con avidez un estilo, se fascina por los simbolistas, sobre todo por Verlaine. Escribe su primer y único drama: $A$ brillant carrier, y se lo propone a W. Archer para ser publicado, pero resulta ser un ibsenísimo disparate, tan impublicable como la poesía que también escribe por esa época, y que contiene demasiadas tinieblas, expresamente byronianas y yeatseanas. Duda entonces de la calidad de su poesía y de su drama ${ }^{4}$.

Pero en prosa la experiencia es otra. De 1900 a 1903 Joyce escribe una serie de textos a los que denomina -con el ánimo de no imitar a nadie-Epifanías y que define como manifestaciones espirituales intempestivas, misteriosas, donde simples objetos y casuales

3 Esta broma de Gogarty no deja de ser irónica. Stanislaus relata que la primera maestra de Jim fue su niñera Mrs. Riordan a la que llaman Dante -este mismo personaje aparece en el Retrato-, ella le enseña a leer y escribir, le da algunas bases de aritmética y geometría, y sobre todo, intenta infundirle un "catolicismo fanático y un amargo patriotismo anti inglés" (Joyce, 2000, p. 28). Dante es una "monja arrepentida", con un fracasado matrimonio a cuestas, ultracatólica, supersticiosa y fascinada con terribles fantasías sobre "El último día", con lo cual alimenta terrores en el pequeño Jim, quien entraba en pánico ante los truenos y los relámpagos, pue según Dante, estos eran los vehículos del poder divino y de su cólera. Según Stanislaus, Jim siempre tuvo horror a los truenos -miedo que también aparece en el Retrato y en Finnegans Wake- y cuando se le preguntaba la razón, respondía: "A ti no te educaron en la Irlanda católica".

$4 \quad$ En marzo de 1901, Joyce le escribe una carta a Ibsen donde reitera su convicción acerca de la misión de artista, que consistiría en transmitir sus epifanías. En esa carta se presenta a sí mismo como adalid, defensor y difusor de la obra del noruego en Dublín, donde ha gritado su nombre, ha reclamado un lugar para él y ha destacado su máxima virtud: "la fuerza sublime de su despersonalización”. Pero también le dice que se ha guardado para sí lo que más le une a él: lo que ha captado de su vida, de las luchas que se libran en el "interior de su frente", de su "decidida resolución de arrancarle los secretos a la vida", y su "indiferencia hacia los cánones", lo cual le permite "seguir adelante a la luz de su heroísmo interior" (“Carta a Ibsen”, cita en Ellmann, 2000, p. 106). 
instantes de repente son radiantes medios de revelación que el escritor debe registrar por escrito del modo más meticuloso posible. Epifanías o instantes de luminosa clarividencia donde convergen todos los tiempos y el artista alcanza una comprensión otra y más profunda de ínfimos trozos de existencia; momentos donde lo vulgar muestra su dimensión sagrada instando al artista a retener en las palabras y en las letras al menos un destello de dicha experiencia.

El artista es pues el encargado de tales revelaciones, en la medida en que se abandona, se evade y puede ver de otro modo, puede tener otra relación con las palabras, las pondera y padece sus consecuencias, las mira de frente: como mirando el sol con los ojos abiertos de par en par. Las epifanías, algunas incluidas en Stephen el héroe, le confirman a Joyce su misión de artista: transmitir las rutilantes manifestaciones de la vida cruda, del más acá, del lado llano y vulgar del mundo que pasa desapercibido para el común de los dublineses. El joven recibe y registra tales impresiones, las toma como "palabras para su granero" encontradas por azar en las tiendas, en los anuncios, en los periódicos, en frases sueltas y trozos de conversación que casualmente escucha en boca de viandantes anónimos. Cada que Dedalus escuchaba epifanías

\begin{abstract}
las repetía para sí hasta que perdían para él todo el significado momentáneo y se convertían en vocablos maravillosos. Estaba decidido a luchar con toda la energía de su alma y su cuerpo contra toda posible entrega a lo que consideraba ahora como el infierno de los infiernos -la región donde todo resulta ser obvio-, y el santo que en otro tiempo fue avaro de lenguaje en obediencia a un mandato de silencio, podía ahora reconocerse en el artista que se aleccionaba para el silencio, no fuera a ser que las palabras le devolvieran su descortesía. Le llegaban frases pidiendo ser explicadas. Se decía a sí mismo: tengo que esperar a que me llegue la Eucaristía, y luego se ponía a traducir esa expresión al sentido común. Se pasaba días y noches martillando ruidosamente para edificarse una casa de silencio en la que pudiera esperar su Eucaristía [...] (Joyce, 1978, pp. 23-24).
\end{abstract}

Convertido en "casa de silencio" ambulante, Dedalus era todo ojos y oídos, en abierta receptividad a todas las impresiones que recibía como si de la Eucaristía se tratase, hasta que descubre que es inútil seguir errando, de modo que regresa a su otra casa "con paso decidido, inflexible, reuniendo palabras y frases sin significado, con decidida seriedad inflexible" (Joyce, 1978, p. 4).

Pero no solo del mundo exterior recoge palabras para su granero, también se impone captar en su escritura

el más elusivo de sus estados de ánimo y organizaba cada verso no palabra por palabra sino letra por letra. Leyó a Blake y a Rimbaud, sobre los valores de las letras e incluso permutaba y combinaba las cinco vocales para construir los gritos de las emociones primitivas (Joyce, 1978, p. 25).

Este nuevo fervor no se compara con ninguno de los que habían ocupado su corazón; “el monje ahora no le parece más que la mitad del artista", aún para expresar lo más sencillo, este debe trabajar arduamente y pagar por adelantado cada momento de inspiración.

En una conversación con su madre -que le anima a seguir el consejo del padre de abrirse paso en la vida, puesto que esta no es siempre como uno lo imagina y que ya quisiera ella "dejar esta vida de verdad y entrar en otra..."- el joven advierte:

¡el arte no es una escapatoria de la vida!, al contrario, es la misma expresión central de la vida. Un artista no es un tipo que cuelga un paraíso mecánico delante del público. Eso lo hace el cura. El artista afirma la plenitud de su propia vida y crea [...] (Joyce, 1978, p. 82).

En otra ocasión, escucha una entrecortada y apagada conversación entre una mujer y un hombre, a partir de lo cual escribió los vertiginosos versos titulados "Villanella de la Tentadora". Esta brizna cotidiana de la que supo extraer poesía, le permite aclarar aún más qué se entiende por epifanía: 
Una súbita manifestación espiritual, bien sea en la vulgaridad de lenguaje y gesto o en una frase memorable de la propia mente. Creía que le tocaba al hombre de letras registrar esas epifanías con extremo cuidado, visto que ellas mismas son los momentos más delicados y evanescentes (Joyce, 1978, p. 216).

Cada epifanía es pues una experiencia de destellos fugaces y frágiles, en extremo difíciles de captar en el lenguaje. De donde cabe decir que ese estado de clarividencia coincide también con la limitación de la palabra y del relato para fijarlo y transmitirlo.

Aunque no se use explícitamente el término epifanía en el Retrato, se pueden leer pasajes como el siguiente, donde -en medio del diálogo sobre estética que Stephen sostiene con Lynch- potencia el sentido que se le da a las epifanías o "relámpagos de intuición", de tan "diáfana claridad" que disuelven y calcinan el mundo que pisa el joven Stephen. Estos destellos le revelan también que toda la ciencia a la que consagra sus días, alejado de los otros, no es más que un "almacén de máximas de la poética y la psicología de Aristóteles" y de Santo Tomás; en suma, que su pensamiento es un "crepúsculo de dudas y de desconfianza", pero cuando se exponía a tales relámpagos

\footnotetext{
su lengua se anudaba y sus ojos permanecían mudos ante la mirada de los demás, porque se sentía envuelto en un manto en el espíritu de la belleza [...] Pero cuando le abandonaban estos breves raptos de silencioso orgullo, se sentía contento de hallarse entre las otras vidas vulgares, de seguir su camino impávido y con alegre corazón a través de la miseria, el bullicio y la indolencia de la ciudad (Joyce, 2012, p. 242).
}

Según Umberto Eco, la noción de epifanía la habría recibido Joyce del crítico literario e historiador del arte inglés Walter Pater. Pero, como se ve en Retrato, Joyce la depura y la aproxima, en primer lugar, a la "luminosidad" de la que habla Santo Tomás, la misma "quidditas de los escolásticos". Esta cualidad suprema, dice Stephen, es "sentida por el artista en el momento en que la imagen estética es concebida en su imaginación” (Joyce, 2012, p. 293). Y, en segundo lugar, trae a colación a Shelley, quien compara la mente en el momento de concebir la imagen estética con "un carbón encendido que se extingue" (Joyce, 2012, p. 293). De modo que

\footnotetext{
El momento en el que la suprema cualidad de la belleza, la neta luminosidad de la imagen estética, es aprehendida en toda su claridad por la mente, suspensa primero ante su integridad, y fascinada por su armonía, la luminosa y callada stasis de la deleitación estética, estado espiritual semejante a aquel otro del corazón, el cual, usando una frase casi tan bella como la de Shelley, el fisiólogo italiano Luigi Galvani llama el encantamiento del corazón (Joyce, 2012, pp. 293-294).
}

Pero en Ulysses, el mismo Dedalus se muestra abatido y se refiere al ambicioso proyecto de escribir las epifanías como algo ya desestimado, pues resulta en extremo arduo transmitir en palabras lo que en sí mismo es evanescente e intangible, sería preciso epifanizar el lenguaje para captar la vida y sus acontecimientos en cada uno de sus destellos. Aunque el autor ironiza acerca de sus epifanías -escritas en hojas verdes ovaladas y dispuestas para que, en la eventualidad de que él muriera, fueran enviadas a todas las bibliotecas del mundo, incluida la de Alejandría-, lo cierto es que estas no le abandonarán, pues ¿qué son en buena medida sus obras sino construcciones de palabras que hacen existir indistintamente la evanescencia y la levedad de lo vulgar y lo memorable, de lo absurdo y de lo oscuro, del sentido nunca estable y del equívoco siempre latente? Carácter epifánico tienen para Joyce las cartas sin puntuación que le escribía su madre. De igual modo, su esposa Nora Bernacle será para Joyce la concreción de la búsqueda de lo extraordinario en lo ordinario, en tal sentido es la epifanía de su vida: de mínima educación, provinciana, humilde, ajena a la literatura, pero con ingenio y energía sin igual. Su relación con Joyce no surge de un arrebato aturdido, sino que siempre estuvo en su vida tal como llegó: paseando con indolencia. En carta del 29 de agosto de 1904, y con temor 
a que Nora le conociera tal como era, le relata frenéticamente pormenores de su vida, de su naturaleza descreída, vagabunda y volátil:

\begin{abstract}
¿No crees que debes conocerme en todos los sentidos? Mi espíritu rechaza la totalidad del actual orden social y la Cristiandad: el hogar, los valores establecidos, los estilos de vida y las doctrinas religiosas. ¿Cómo podría amar la imagen de un hogar? El mío era un simple producto de la clase media arruinada por un sentido del derroche que yo he heredado. A mi madre la mataron lentamente los malos tratos de mi padre, las dificultades de todo orden y, estoy seguro, el cinismo de mi comportamiento. En mi familia éramos diecisiete, mis hermanos y hermanas no significa nada para mí. Solo uno de mis hermanos es capaz de comprenderme. [...] No puedo integrarme en el presente orden social más que como vagabundo (cita en Ellmann, 2002, p. 193).
\end{abstract}

Con su lenguaje llano, Nora será su cómplice incondicional que, sin embargo, nunca se interesó por los idiomas ni por lo que escribía Jim, y que a duras penas sobrevivía doblemente exiliada en cada ciudad europea y en cada lengua por la que, con gran facilidad, discurría Joyce.

Igualmente, epifánicos serán los delirios y alucinaciones de su hija Lucía, considerada por el mismo Joyce como clarividente, al fin y al cabo, Luz, Lucía, patrona de la visión, la visión que va perdiendo Joyce paralelamente a su inmersión en la más extraña de todas sus invenciones: Finnegans Wake ${ }^{5}$. Nada explica la epifanía, ella se basta y el resto se redefine por ella. De ese modo, se rompe la temporalidad lineal y se desvela el

carácter fundante, ex nihilo de una operación que se exceptúa ella misma y se ofrece como elemento operador único para el presente, el pasado y el futuro. La epifanía se exceptúa con respecto a la realidad, pero, ¿es ésta, la realidad, un continuum, un fondo homogéneo del que la epifanía se ha desgajado? ¿Cómo entender aquí la realidad? [...] Todo lo que rompa la linealidad cabe en Joyce, todo lo que dinamite el sentido común interesa a Joyce (Marco, 2015, pp. 91 y 93).

En la epifanía joyceana, algo -objeto o palabra- adquiere un estatuto real, que irrumpe y estalla o pone en vilo la consistencia imaginaria y simbólica de la realidad. Algo se desprende de su sentido ordinario e introduce o hace visible una profunda disimetría. Ver-oír la palabra-imagen hasta enrarecer el espacio y el tiempo, tanto, que es preciso cerrar los ojos para ver, para experimentar esa visualidad desgarrada, esa cascada incontenible de memoria que escapa tanto al objetivismo como a la trascendencia. En Ulysses, la epifanía remite a al poder de "pensar con los ojos", a la "ineluctable modalidad de lo visible", a la esquicia entre el ver y el mirar, en la cual se abandona el protagonista.

\title{
2. El artista mirado por las palabras
}

Las [palabras] que no comprendía se las repetía una y otra vez hasta que se las aprendía de memoria y a través de ellas le llegaban vislumbres del mundo que le rodeaba.

Joyce (2012, p. 83).

En Retrato del artista adolescente, Joyce disecciona la miseria familiar, los terrores que infunde la religión, los ideales y prejuicios en que se sostiene el discurso educativo, y el fanatismo

$5 \quad$ El año de 1932 es muy importante para el escritor, no solo por la muere del padre, sino también por el nacimiento de su primer nieto, llamado Stephen en honor al abuelo. Pero es también el año en que Joyce padece por la enfermedad de su hija Lucía, a partir de lo cual "busca, una vez más, la exactitud fulgurante conquistada en el uso riguroso de la escritura: nombra el estado de su hija con un desdoblamiento del nombre que ya le había dado -Lucía, la Clarividente - y esa renominación no deja de ser, también, una apelación frente a la oscuridad que, tal como su obra, progresivamente se hace cargo de sus ojos porque, en ese mismo período, los problemas de visión de Joyce se agravan al punto de dejarlo prácticamente ciego" (Laia, 2001, p. 4). 
político que contamina la cotidianidad, y para hacerlo se vale de recurso de las epifanías, del análisis minucioso de los discursos - como el de la estética de herencia tomista- y, sobre todo, de una reivindicación de la escritura y de la creación en general como experiencia ajena a todo compromiso popular, esteticista, canónico y moral.

Lejos de considerar que el Retrato es el de un Joyce que ya no existe, como sugiere Eco, lo que está allí en juego es nada menos que la gestación del lugar que ocupará el irlandés en la literatura del siglo XX: hacerse un nombre propio, o hacerse padre de sí mismo -de ahí que el paradójico nombre del artista sea decisivo-; es el embrión de las obras siguientes, allí está en germen el estatuto de la letra en el inconfundible estilo de Joyce.

Pequeño, débil, temeroso, de ojos débiles y aguanosos, pero ante todo ávido de conocer y en extremo receptivo a todo cuanto escucha. Aunque su nombre es objeto de burla y su padre no es digno como los otros padres, en su mayoría "magistrados", sin embargo, Stephen Dedalus es indomeñable en su fragilidad. En su fascinación por las palabras, las letras y las frases, este joven toma distancia de las cosas y de los otros, y se aísla o se exilia en el tono impersonal. "Qué bien se estaría echado sobre la esterilla delante del fuego, con la cabeza apoyada entre las manos y pensando estas frases" (Joyce, 2012, p. 14).

Ante las inevitables bromas y crueldades escolares, Stephen no delata a nadie -tal como se lo advierte el padre cuando lo deja internado en Clongowes-, pero tampoco guarda rencor a Wells por haberlo empujado a la fosa, ni a los que se burlan de su nombre, ni a los que le vacilan acerca de dar o no un beso a la madre antes de ir a dormir, ni al pequeño vándalo que rompió sus gafas... Pero eso sí, a Dolan, el prefecto de estudios, apodado la lavandera, sí que lo denuncia con todo el coraje ante el Rector, no tanto por haberse ensañado con la palmeta -por el asunto de las gafas- sino por haberlo llamado "maulero" y "trapisondista". Esa fue la verdadera crueldad, la canallada y humillación inaceptable. Lo "estuvo rumiando", pero al fin y al cabo la historia estaba llena de esos hombres y de sus actos, así que mejor sería olvidar, "ponerse a un lado. Cuando uno es pequeño lo mejor es escapar inadvertido" (Joyce, 2012, p. 73). No obstante, maulero y trapisondista no sería jamás, por eso se decide y acude al Rector, apodado calavera, y pone el denuncio con fría objetividad. Regresa al campo de juegos, libre y sin envanecimiento alguno.

Siempre fiel a las palabras: "Las que no comprendía se las repetía una y otra vez hasta que se las aprendía de memoria y a través de ellas le llegaban vislumbres del mundo que le rodeaba" (Joyce, 2012, p. 83). Joyce dice vislumbres donde antes, quizá, diría epifanía. Cuando más de cerca miramos las palabras más lejos miran ellas desde atrás, diría Karl Kraus.

En el paréntesis de su educación jesuita, a causa de la precariedad económica, Stephen Dedalus vagabundea, buscando en el mundo real "la imagen irreal que su alma contempla constantemente" (Joyce, 2012, p. 87). Cuando la encuentre, "la debilidad, la timidez, la inexperiencia, caerán de él en aquel momento mágico” (Joyce, 2012, p. 87). Pero al mismo tiempo ve crecer en sí mismo el vago descontento, el humor silencioso, el enfado por ser niño con "arrebatos de intranquila locura" y por el "cambio de fortuna" que convierte su mundo en "pesadilla de mentiras y suciedades". No obstante, la oscuridad de estos sentimientos no entorpece su visión y, gracias al "encanto del aislamiento", podía archivar "con paciencia cuanto veía, manteniéndose aparte de todo ello, gustando en secreto su aroma corrompido" (Joyce, 2012, p. 90).

De regreso con los Caballeros de la Educación -con los que, según su padre, podría labrarse un futuro-, Dedalus se convierte en objeto de burla por ser ejemplar y modelo en todo. 
Razón por la cual, Heron, el líder, se empeña en encontrar el punto exacto en que Dedalus se sobresalta, y ese punto es el padre, cualquier alusión a él lo saca de casillas. Pero lo suyo es la composición literaria, en ello le va todo el tiempo, en prosa prefiera a Newman, y en poesía el más alto lugar lo tiene Byron, entre otros escritores subversivos cuyos "sarcasmos y virulencias fermentaban lentamente en su cerebro" (Joyce, 2012, p. 105). Después de una clase en la que el profesor Tate señalara en público una "herejía" en el ensayo de Dedalus, Heron insiste en provocarle y para ello se confabula con Nash, el azote de la clase, y con Boland, el más vago de todos, para fastidiar diciendo que Byron es un poeta "para gente sin educación", "herético e inmoral”, asunto que Dedalus debería reconocer y confesar, pero a él le tiene sin cuidado.

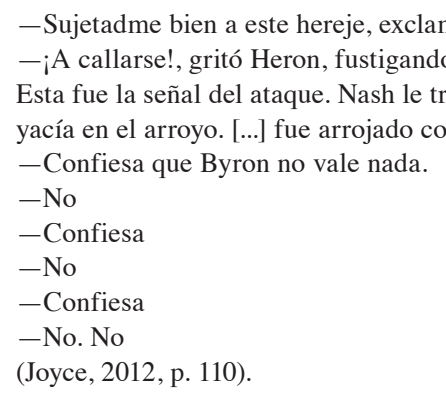

Este incidente, que no fue ni inventado ni exagerado -y que fue de tal alcance que, como recuerda su hermano Stan, la madre hubo de remendar sus ropas para que pudiera ir al colegio al día siguiente-, llama la atención, entre otras cosas, porque Joyce se presenta como zafado e indiferente ante el propio cuerpo sometido a semejante humillación y maltrato, de hecho, cuando al fin los verdugos le suelten, curiosamente Stephen

recitaba el Confiteor entre las risas indulgentes de los otros dos y mientras las escenas de este ultrajante episodio pasaban incisivas y rápidas por su imaginación, se preguntaba por qué no guardaba mala voluntad a aquellos que le habían atormentado. No había olvidado en lo más mínimo su cobardía y su crueldad, pero la evocación del cuadro no le excitaba al enojo. A causa de esto, todas las descripciones de amores y de odios violentos que había encontrado en los libros le habían parecido fantásticas. Y aun aquella noche, al regresar vacilante hacia casa a lo largo del camino de Jone, había sentido que había una fuerza oculta que le iba quitando la capa de odio acumulado en un momento con la misma facilidad con la que se desprende la suave piel de un fruto maduro (Joyce, 2012, pp. 110-111).

En otra ocasión, un poder semejante a esa fuerza oculta le hace detener la frenética y frustrada búsqueda de una mujer, después de la función teatral en la que Stephen Dedalus actúa.

\footnotetext{
Apenas si sabía adónde iba. Orgullo, esperanza y deseo, como hierbas pisoteadas en su corazón, elevaban humaredas de un incienso enloquecedor que cual una cortina cegaba las luces de su espíritu. [...] Se elevaron ante sus ojos angustiados en una densa y enloquecedora humareda, fluyeron y se desvanecieron sobre él. [...]

Un poder semejante a aquel que otras veces había hecho desaparecer de él la cólera o el resentimiento, fue el que le hizo pararse.

Se detuvo y se quedó mirando el sombrío pórtico del depósito de cadáveres y la callejuela empedrada de al lado. Vio el nombre de la callejuela, Lotts, escrito en la pared, y respiró despacio el aire rancio y denso que de ella salía. -Esto son orines de caballo y paja podrida -pensó-. Es bueno respirar este olor. Me calmará el corazón. Ahora mi corazón está ya absolutamente tranquilo. Regresaré (Joyce, 2012, p. 116).
}

Ese poder y esa fuerza oscura desvanecen la cólera en él, lo aquietan y le hacen detenerse; se diría que de ahí toma el aliento para evadirse y mantener sus hábitos de tranquila obediencia, de modo que el zumbido o las voces de los otros no le arrastren. Escéptico ante los ideales que otros le quieren inculcar, así es como se sitúa en el mundo el joven Stephen Dedalus: la camaradería es mera anticipación de la virilidad, la invitación a ser buen caballero 
y buen católico son palabras vacías, tanto como lo son aquellas que quieren convencerlo de ser atlético y saludable, o aquellas que lo instan a ser fiel a la patria, la lengua y las tradiciones; y ni se diga de las palabras que lo invitan a reconstruir la derruida hacienda del padre... Solo presta atención por unos instantes a ese murmullo, a ese zumbido que le llega desde distintas direcciones, de modo que sus compañeros se convierten en presencias fantasmales, frente a las cuales basta un poco de paciencia.

Dedalus procede, en estas escenas donde otros intentan ponerlo a prueba, con extraña ajenidad frente al propio cuerpo y frente al propio deseo. Como si de repente estuviera desvinculado del "sí mismo", del narcisismo más elemental, como si el cuerpo no fuese lo más preciado, como si no hubiera en él la fuerza necesaria para defenderlo a toda costa. Sin afección ni resentimiento, experimenta su cuerpo apaleado desprendiéndose de sí mismo como la cáscara de un fruto maduro; de igual modo, el deseo, el orgullo y la esperanza truncados no le suscitan airadas frustraciones, por el contrario, la humareda se disipa rápidamente y algo tan elemental como el olor a establo calma su corazón. A propósito de la paliza arriba citada -que parece representar todas las situaciones en las que el joven Joyce llegó a ver comprometido el propio cuerpo, sin apenas reaccionar, como si no fuera el propio-, Lacan se pregunta "¿Qué nos indica esto si no algo que concierne en Joyce a la relación con el cuerpo, relación ya tan imperfecta en todos los hombres? ¿Quién sabe lo que pasa en su cuerpo?” (Lacan, 2013, p. 146). No es un asunto que se explique apelando al inconsciente, puesto que este "no tiene nada que ver con el hecho de que uno ignore montones de cosas de su propio cuerpo" (Lacan, 2013, p. 146). Lo que Joyce testimonia es del orden de la psicología de la relación con el cuerpo, pues "la psicología no es otra cosa que la imagen confusa que tenemos de nuestro cuerpo. Pero esta imagen implica afectos" (Lacan, 2013, p. 147). En esta relación "hay algo psíquico que se afecta, que reacciona, que no está separado, a diferencia de lo que testimonia Joyce", pues en él "solo hay algo que no pide más que irse, desprenderse como una cáscara. Resulta curioso que haya gente que no experimente afecto por la violencia sufrida corporalmente" (Lacan, 2013, pp. 146-147).

Semejantes experiencias de desprendimiento del cuerpo como si fuera algo ajeno ponen en vilo la expresión corriente según la cual "uno tiene su cuerpo", hasta tiene un alma. Pero dejar caer el cuerpo de este modo, como si la golpiza se la hubiesen dado a otro, o como si el deseo y el orgullo pisoteados como hierbas fueron los de otro, no deja de "ser sospechoso", porque tener un cuerpo es tanto como decir tener un yo, un ego, un amor propio, un narcicismo, ¿quién no los tiene? Si el ego es narcisista es porque existe algo que "sostiene el cuerpo como imagen", y si en eventos como los referidos por Joyce esa imagen no está implicada, entonces el ego en él opera de modo muy particular, es decir, funciona como rueda suelta. En efecto, lo imaginario estaría desanudado de lo simbólico y de lo real, entonces se trataría en Joyce de un nudo maltrecho, donde la escritura y la obstinación por las palabras serían la suplencia o el "ego corrector". Su texto tendría entonces la estructura de nudo borromeo, pero Joyce no lo sabe. Su obra es un saber hacer con algo que falla, con el síntoma que él mismo inventa.

Que Joyce resulte críptico, ilegible o antipático no es algo al margen de este modo de operar lo imaginario -la imagen del propio cuerpo- como rueda suelta. Su escritura laberíntica, con enigmas a granel, es algo con lo que Joyce juega, convirtiéndose en el artista del equívoco, y sabe que con ello dejará trabajo por siglos para los universitarios, tan necesitados como viven de alimentarse de los enigmas. “QQué Joyce sea por excelencia el escritor del enigma no sería 
la consecuencia del ensamblaje tan mal hecho de este ego, de función enigmática, de función reparadora?" (Lacan, 2013, p. 151).

Con el mismo tono, abandonado a ese poder o a esa fuerza que lo desposee de su cuerpo, de su imagen, del sí mismo, Joyce-Stephen Dedalus acompaña a su padre a su natal Cork a subastar los bienes, pero esto se le impone como una ruda desmentida de su fantasía, y como una mera constatación de la precariedad de los bienes. Pero lo más llamativo es que el joven escucha sin asombro alguno al padre locuaz, tan afanado en mostrarle cada cosa, en presentarle a los lugareños, en recorrer los espacios de su juventud, en beber y brindan en cada taberna a la "memoria de su pasado". Stephen lo escucha y lo observa sin interés, sin piedad, sus muertos le resultan del todo extraños. Pero en el anfiteatro de anatomía, donde otrora el padre pretendió estudiar medicina, de repente, en un pupitre,

leyó la palabra Feto grabada varias veces en la madera obscura y manchada. Esta palabra sobrecogió su espíritu; le pareció sentir en torno de él a los ausentes estudiantes del colegio y espantarse de su compañía. Y una visión de la vida de ellos que las palabras de su padre habían sido incapaces de evocar, se elevó ante sus ojos como si brotara de las letras grabadas en la mesa.

$[\ldots]$

Sueños monstruosos le acudieron en tropel a la memoria. También ellos habían brotado furiosamente, de improviso, sugeridos por simples palabras. Y él se había rendido y los había dejado filtrarse por su inteligencia y profanarla, sin saber nunca de qué caverna de monstruosas imágenes procedían, dejándole siempre, tan pronto como se desvanecían, débil y humilde ante los demás, asqueado de sí mismo e intranquilo (Joyce, 2012, pp. 120-121).

El joven sale en compañía del padre y escucha otra vez las mismas historias y los nombres de "aquellos calaveras" que habían sido sus compañeros de juventud, y de repente es como si viera en todo ello su "propia y equívoca posición en el Belvedere": el primero de la clase, con temor del poder de sí mismo, extraviado en la miseria de su propia vida, expuesto al tumulto de pensamientos:

Aquellas letras grabadas en la manchada madera del pupitre le estaban contemplando fijamente, como si hicieran befa de su flaqueza corporal y de sus fútiles entusiasmos, le provocaran a la repugnancia de su propia locura y de las asquerosas orgías de su mente (Joyce, 2012, pp. 122-123).

Mirado por las letras, contemplado y burlado por ellas; mirado desde muy lejos por las palabras y por la vida cruda, embrionaria, informe: la de su padre y la de "los calaveras" que fueran sus colegas, pero sobre todo la mirada de esas letras lo reconducen a su propio estado embrionario, informe, evadido, con un alma vieja...

-Yo soy Stephen Dedalus. Voy andando junto a mi padre que se llama Simón Dedalus. Estamos en Cork, en Irlanda. Cork es una ciudad. Nuestra habitación está en el Hotel Victoria. Victoria, Stephen, Simón. Nombres.

Se le nubló de repente el recuerdo de su niñez. Trataba de evocar sus vívidos incidentes y no podía. Sólo recordaba nombres. Dante, Parnell, Clane, Clongowes (Joyce, 2012, p. 125).

Al borde de ese abismo que se acrecienta entre él y el mundo de su padre y de los otros, Stephen se experimenta como si estuviera "derivando por la vida como la cáscara estéril de la luna", tal como se lo sugieren los memorables versos Shelley: “¿Viene tu palidez de aquel hastío / la tierra, ¡oh!, tú la errante y solitaria?” (Shelley, citada por Joyce, 2012, p. 129). En esta asociación de "triste esterilidad y actividad de vastos ciclos extrahumanos refrigeró el espíritu de Stephen. Y se olvidó de su propio dolor, estéril y humano" (Joyce, 2012, p. 129).

Cabe preguntarse qué es para Joyce el acto de escribir, en qué cree cuando escribe, si es que cree en algo, qué se cree él cuando escribe. Es difícil saberlo, sobre todo teniendo 
en cuenta que "cuando se escribe se puede tocar lo real pero no lo verdadero", como advierte Lacan (2013, p. 77), quien advierte que todo el cúmulo y el laberinto de notas, apuntes, cartas, esbozos, versiones dejador por Joyce, tienen el efecto de extraviar y exiliar al lector. Leer no basta para saber lo que se creía Joyce.

¿Se creía redentor? Aunque en sus diálogos Cranly (Byrne) lo insta a reconocer que ya no cree en la doctrina de la Iglesia, Stephen lo evade, lo deja en suspenso, pues rechazar ese aparato sería rechazar aquello que lo sostiene, escribe sobre las consecuencias de ese andamiaje, pero “¿por dónde pasaban las paralelas que lo orientaban cuyos secretos él en suma da: el exilio, el silencio, la astucia?” (Lacan, 2013, p. 77). ¿Se cree redentor acaso?, Jacques Aubert, el gran joyceano-lacaniano, responde que existen marcas de ello, pero son confusas.

Joyce, a través de Stephen Dedalus, es el artista, y ello no supone o no coincide con ser redentor, sino Dios creador. ¿Cómo, pese a todo, Joyce no estuvo loco mientras que su hija Lucía sí lo estuvo? No serlo tampoco fue un privilegio, claro está. ¿Acaso Joyce mediante el obstinado deseo de ser el artista - con lo cual mantendría ocupado al discurso universitario hecho de semblante- compensaba la falla de su padre-feto? ¿Compensaba así el abandono de ese padre que delegó toda su función de padre -aunque le daba trato de hijo único, prefiriéndolo claramente por encima de los otros hijos- en los diplomáticos jesuitas? ¿Cómo entender tal confianza del padre en los Caballeros de la Educación mientras él mismo se reconocía como un renegado del catolicismo? ¿Cómo inscribe Joyce todo esto? ¿En qué sentido el Retrato es un intento de anudar semejante inconsistencia paterna?

Allí donde el padre dimite, el hijo se ve instado a compensar su dimisión, y para ello su único recurso son las palabras, las letras, la escritura, con todo lo cual se hace un mundo, un nombre, un padre, se hace padre de él mismo en tanto crea una obra que tiene el carácter de sinthome 6 , antigua escritura de symthôme. En este punto, Lacan fabrica una palabra de doble fondo, como se suele decir, para aproximarse a la escritura de Joyce, valiéndose de la homofonía de Symthome, sinthome, saint homme, Saint Tomas. Sin (pecado), homme (hombre), home (home rule: ley de autonomía en los combates por la independencia irlandesa). Joyce estaría entre:

a) el sinthomadaquin, o lo que en su obra es ortodoxo y tomasdeaquinizado, como lo que Eco insiste en llamar la escolástica que atraviesa la obra, como "ropaje", "actitud mental" o "modus operandi" que se esfuerza por alcanzar un universo ordenado -al modo de las Summae - en tensión con el universo que se expande. Así, Santo Tomás sería la auctoritas de la forma, bajo la cual Joyce "pasa de contrabando una estética

$6 \quad$ "Joyce el síntoma" es el título de la conferencia que Lacan dicta el 16 de junio de 1975, por invitación de Jacques Aubert al V Simposio Internacional James Joyce, conferencia incluida en el Seminario 23, El Sinthome, 1975-6. En dicha conferencia, a continuación de Marie Jolas, Lacan empieza por anotar las casualidades que nunca lo son, y que tejen el destino. "Cuando salía de un ambiente bastante sórdido, de Stanislas, para decir su nombre - educado por curas, ¡vaya!, como Joyce, pero por curas menos serios que los suyos, que eran Jesuitas, y sabe Dios lo que él supo hacer con ello-, en resumen, cuando emergía de ese ambiente sórdido, resulta que, a los diecisiete años, gracias a que frecuentaba [La Maison des amis des Livres, fundada por] Adrienne Monnier, me topé con Joyce. Así como asistí, cuando tenía veinte años, a la primera lectura de la traducción francesa que había aparecido de Ulises. Las casualidades nos empujan a diestra y siniestra, y con ellas construimos nuestro destino, porque somos nosotros quienes lo trenzamos como tal. Hacemos de ellas nuestro destino porque hablamos. Creemos que decimos lo que queremos, pero [...] somos hablados" (Lacan, 2013, p. 160). 
original como comentario de las ideas de Aquino. [...] Aquino es el modelo para entender las poéticas de Joyce" (Eco, 2000, p. 24). Para Lacan, el sinthomadaquin es el síntoma elevado a la condición de semblante o vitrina que exhibe todos los accesorios y la herencia intelectual, todo el discurso sobre la estética, por ejemplo, y todo el lenguaje litúrgico, con lo que ello implica de sublimación o de escabel.

b) y el sint'home rule -en la medida en que Joyce hace de la indiferencia política una regla del hogar: home rule- es el sinthome herético, desnudo en su estructura, en su real, sin el madaquinismo, pero ello no impide la obra. El sinthome rule es sinthome roule, con rueditas, que consiste en una versión de un discurso que no es del semblante, es un discurso otro que nace de un saber hacer con lo real, con el goce no simbolizable.

El asunto es que Joyce, como buen hereje, elige el camino por el cual alcanzar la verdad... no toda: una vez reconoce la naturaleza del síntoma no se priva de usarlo hasta alcanzar su real y calmar su sed. Conjuga el sinthomadaquin con el sinthome roule, sin que ello implique que sea tomista o desatadamente loco o rueda suelta. Más bien, es saint homme, que goza-padece el arte de la letra que supo crear. Que su arte sea sinthome quiere decir que Joyce asume la misión y la función de hacer subsistir a su familia, de darle nombre y lustre, y de hacer célebre la "conciencia increada de su raza" (Joyce, 2012, p. 351). Es el artificio apuntando a lo que se presenta como síntoma. Desde el Retrato, Joyce cree en la conciencia increada de su raza y como tal se dispone a forjarla "en la fragua de su espíritu", pide amparo a su padre indigno y carente, al que pese a todo se mantiene "arraigado mientras reniega de él. Ese es justamente su síntoma” (Lacan, 2013, p. 68). Desde sus tempranos ensayos y desde Retrato del artista adolescente, hasta Finnegans Wake, Joyce sostiene

\footnotetext{
una cierta relación con la palabra: a saber, descomponer, destrozar, esa palabra que va a ser escrita, hasta tal punto que termina disolviendo el lenguaje mismo. [...] él termina imponiendo al lenguaje mismo una especie de quiebre, de descomposición, que hace que ya no haya identidad fonatoria.

Sin duda, hay en ello una reflexión sobre la escritura. Por medio de la escritura, la palabra se descompone imponiéndose como tal, en una deformación de la que resulta ambiguo saber si se trata de liberarse del parásito palabrero o de dejarse invadir por las propiedades del orden esencialmente fonémico de la palabra, por la polifonía de la palabra (Lacan, 2013, p. 94).
}

Cómo es que, se pregunta Lacan, el humano corriente no se percata de que las palabras, de las que depende realmente, le son impuestas. En tal sentido, la palabra es parásito, revestimiento o dolencia que nos aqueja sin darnos cuenta. Algunos, como Joyce, se percatan, su obra es un gran darse cuenta de ello: es la obra de un hombre-feto, que como tal no tiene cuerpo; la de un santo hombre mártir de la letra en su laberinto.

El 29 de diciembre de 1931, muere el padre de Joyce. Unos momentos antes le pidió a su hija May que le dijera a Jim que había nacido a las seis de la mañana, dato que Jim le había pedido para hacerse un horóscopo. Como era el único hijo, el cuarto hijo único en la genealogía Joyce, el padre se aseguró de dejarlo como heredero exclusivo, mediante documento notarial, de la suma de 665 libras y nueve chelines.

Y aunque Joyce esperaba hasta último momento un gesto del padre hacia su obra, este nunca dijo ni una palabra, porque no la entendía o porque no le gustaba. Su muerte le deja con gran remordimiento por la huida de Dublín en 1904, y por no haber regresado ni para el entierro, pero tenía sus motivos: esa ciudad era el "terreno de sus enemigos". En medio del duelo, 
confiesa a Mis Weaver que no se siente capaz de terminar Finnegans Wake y que su talento procedía de un rasgo de carácter de su padre.

\begin{abstract}
Era el hombre más necio que he conocido y sin embargo era también cruelmente astuto. Pensó en mí y habló de mí hasta su último aliento [...] cientos de páginas y montones de personajes de mis libros vienen de él. Su seco (o más bien húmedo) ingenio podían hacerme retorcer de la risa. De él me quedan sus retratos, un abrigo viejo, una buena voz de tenor, y una disposición extravagantemente licenciosa (y de la que, de todos modos, procede la mayor parte del talento que pueda yo tener), pero, esto aparte, otra cosa que no sé cómo definir (Carta del 17 de enero, cita en Ellmann, 2002, p. 718).

Si de aquella "disposición extravagantemente licenciosa" le viene buena parte del talento, ¿qué función tiene para él esa "otra cosa” que no sabe cómo definir y que también le viene del padre? “iPobre loco! Parece que su voz, de algún modo entró en mi cuerpo o en mi garganta. Y en estos últimos tiempos, más que nunca, especialmente cuando suspiro" (Carta a Joyce Mis Harriet Weaver, 22 de julio de 1932, cita en Ellmann, 2002, p. 719).
\end{abstract}

\title{
Bibliografía
}

Eco, U. (2000). Las poéticas de Joyce. Barcelona: Lumen.

Ellmann, R. (2002). James Joyce. Barcelona: Anagrama.

Joyce, J. (1971). Escritos críticos. Barcelona: Lumen.

Joyce, J. (1978). Stephen el héroe. Barcelona: Lumen.

Joyce, J. (2000). Cartas de amor a Nora Bernacle. Recuperado de www.elaleph.com

Joyce, J. (2012). Retrato del artista adolescente. Madrid: Alianza editorial.

Lacan, J. (2013). Seminario 23: El Sinthome. Buenos Aires: Paidós.

Laia, S. (2001). La locura de Joyce. Colección DIVA, 26.

Marco, Z. (2015). El tejido Joyce, Un recorrido por Retrato del artista adolescente. Madrid: Arena Libros.

Soler, C. (2003). La aventura literaria o la psicosis inspirada Rousseau, Joyce, Pessoa. Medellín: Editorial No todo.

Svevo, I. (1990). Escritos sobre Joyce. Barcelona: Nexos. 